\title{
Diagnostic Value of Sodium Tolbutamide Test in Hypoglycemia
}

\author{
Kiyohiko Yoshikawa \\ Department of Internal Medicine (Dr. Y. Hatakeyama), \\ Iwaki Kyoritsu Hospital, Iwaki
}

The intravenous Na-tolbutamide test was done on various types of hypoglycemia and the following conclusions were obtained:

(1) Though very useful in the screening of hypoglycemia, the test is not always satisfactory for the differential diagnosis of various types of hypoglycemia.

(2) The diagnosis of hypoglycemia by means of the Na-tolbutamide test is considered practically established when the recovering ability from hypoglycemie levels is absent or insufficient, so as to give a value of the recovery index mostly 0.5 or less, and the stationary value is not higher than $55 \mathrm{mg} / 100 \mathrm{ml}$.

(3) Pronounced hypoglycemia occasionally persists in some cases of functional hypoglycemia. Temporary rise in the blood sugar levels is observed in some cases of pancreatic hyperinsulinism. Differential diagnosis between the two types of hypoglycemia is impossible when only the Na-tolbutamide test is employed.

(4) In a patient with diabetes complicated with hypoglycemia, the blood sugar level 20 and 30 minutes after intravenous tolbutamide injection showed an obvious decrease in the decline rate.

(5) Biphasic fluctuations of blood sugar levels after intravenous tolbutamide injection were observed in three cases of hyperinsulinism.

In 1956, Mirsky et al. ${ }^{1}$ discovered that the effect of Na-tolbutamide on blood sugar in diabetic patients differed from that in normal subjects. In 1958, Unger and Madison ${ }^{2.3}$ stated that the intravenous Na-tolbutamide test was very useful for the diagnosis of diabetes.

In 1961, Fajans et al. ${ }^{4}$ reported the results of their studies on the intravenous Na-tolbutamide test for hypoglycemia, stating that the test was most valuable for the differential diagnosis of pancreatic islet cell tumors from other types of hypoglycemia including functional hypoglycemia.

In the present report the results of the intravenous Na-tolbutamide test on eight patients with various types of hypoglycemia are described.

\section{Subjects and Methods}

Eight hypoglycemic patients from in-patients and out-patients of our hospital were selected for the present study. They consisted of 5 patients with functional hypoglycemia, one with hypoglycemia due to hypoadrenalism, one with organic

Received for publication, June 15, 1967. 
pancreatic hyperinsulinism and one with diabetes of ten years' period, who had often had hypoglycemic attacks and the diagnosis of diabetes had been established on the basis of various examinations. The last case was complicated with hypoglycemia, and it is hereafter referred to as diabetes complicated with hypoglycemia. Fourteen healthy subjects and three patients with liver function disturbance were also examined in the present study.

Two of 5 patients with functional hypoglycemia had developed hypoglycemia after gastric surgery. The patient with organic pancreatic hyperinsulinism had hypoglycemia due to diffuse hyperplasia of pancreatic islets, which was histologically confirmed on specimens of total pancreatectomy.

In cases of disturbed liver functions the Takata reaction, ZTT, TTT, GPT, GOT, BSP and Meulengracht's tests were evaluated. In 3 cases the diagnosis of chronic hepatitis of moderate degree was established by liver biopsies.

I have already reported that the pattern of blood sugar curves in patients with slight diabetes or hypoglycemia are generally characterized by the following four factors: fasting blood sugar level, index or speed of blood sugar decline, index or speed of blood sugar recovery and stationary blood sugar value. The definition of the four factors in the blood sugar curve is diagrammatically presented in Fig. 1.

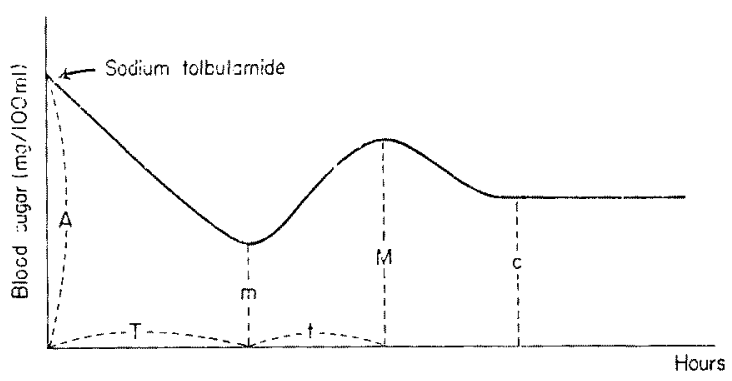

Fig. 1. The blood sugar variations following the intravenous injection of Na-tolbutamide ( $1 \mathrm{~g})$. (Schematic illustration of blood sugar curves)

$A$ : Fasting blood sugar level $\mathrm{m}$ : Minimum blood sugar level

M: Maximum blood sugar level T: Time for decline

$\mathrm{t}$ : Time for recovery c: Stationary value

$\frac{A-m}{T^{-}}:$Index for blood sugar decline $\begin{gathered}M-m \\ t\end{gathered}$ : Recovery index

$\underset{A}{A-m} / T:$ Sensitivity index $\frac{A-m}{A}:$ Maximum decline rate

After a fasting blood sample was taken from the ear lobule of each patient, 10 $\mathrm{ml}$ of Na-tolbutamide (Na-tolbutamide for diagnostic use, supplied from Hoechst Co.) were intravenously injected over a period of three minutes. After the injection, blood was drawn every 10 minutes for 3 hours, and thereafter every 30 minutes 
until 5 hours after the injection. Determinations of blood sugar levels were performed by the method of Fujita and Iwatake. ${ }^{5}$

In the evaluation of blood sugar, the recovering ability after the administration of Na-tolbutamide, the index of recovery from hypoglycemia and the blood sugar stationary value were taken into consideration, as was reported in a previous paper. $^{6}$

\section{RESULTS}

The values of the blood sugar for 5 hours after intravenous injection of Na-tolbutamide in normal subjects and in patients with liver impairment and hypoglycemia are presented in Table 1.

In comparison with the fasting blood sugar levels, the per cent declines of blood sugar levels in 20,30,60,90, 120, 150, 180, 240 and 300 minutes of the injection were presented in Table 2 .

The mean values of per cent declines in all the cases with hypoglycemia were as follows: $29.6 \%$ at 20 minutes; $35.8 \%$ at 30 minutes; $41.6 \%$ at 60 minutes; 37.6 at 90 minutes; $35.6 \%$ at 120 minutes; $27.6 \%$ at 150 minutes; $28.6 \%$ at 180 minutes; $30.4 \%$ at 240 minutes; and $29.5 \%$ at 300 minutes.

The blood sugar decline rates at 20 and 30 minutes were not much different among the different groups and were nearly equal to the values of the normal group. In contrast, the decline rates of the hypoglycemic cases were remarkably higher at $60,90,120,150,180,240$ and 300 minutes, with prominent differences from the values in the normal group and the group of disturbed liver function.

The curves of blood sugar variations in representative cases of each group are recorded in Figs. 2-7. The blood sugar variations following the intravenous injection of Na-tolbutamide in a normal subject, Case 1, showed a radical decline of blood sugar level, a nadir of $50.9 \mathrm{mg} / 100 \mathrm{ml}$ being observed 20 minutes after the determination of the fasting blood sugar of $88.9 \mathrm{mg} / 100 \mathrm{ml}$. Subsequently, a tendency of rapid recovery was noted, and a peak of $85.2 \mathrm{mg} / 100 \mathrm{ml}$ was reached at 50 minutes. Thereafter, the level was stationary until 300 minutes after the injection.

Case 3 of the group with liver function disturbance showed fluctuations in blood sugar levels as shown in Fig. 3. The intravenous Na-tolbutamide produced a decline of blood sugar from the fasting level of $92.2 \mathrm{mg} / 100 \mathrm{ml}$, but the decline was a little slower than that in the normal subjects. A nadir of 57.4 $\mathrm{mg} / 100 \mathrm{ml}$ was reached at 70 minutes. Subsequently, the blood sugar level rose and the recovery to a peak of $103.1 \mathrm{mg} / 100 \mathrm{ml}$ was observed at 60 minutes after the nadir. After a subsequent decline to $71.3 \mathrm{mg} / 100 \mathrm{ml}$, the blood sugar level became then stationary at $71.3 \mathrm{mg} / 100 \mathrm{ml}$.

Case 1 of the group with functional hypoglycemia showed variations in the blood sugar levels as shown in Fig. 4. This case showed a rapid decline of blood sugar level after the intravenous injection of $\mathrm{Na}$-tolbutamide from the fasting blood sugar of $73.0 \mathrm{mg} / 100 \mathrm{ml}$ to $27.9 \mathrm{mg} / 100 \mathrm{ml}$ at 40 minutes and developed 
TABLE 1. Values of the blood sugar for 5 hours after the intravenous injection of hypoglycemic patients

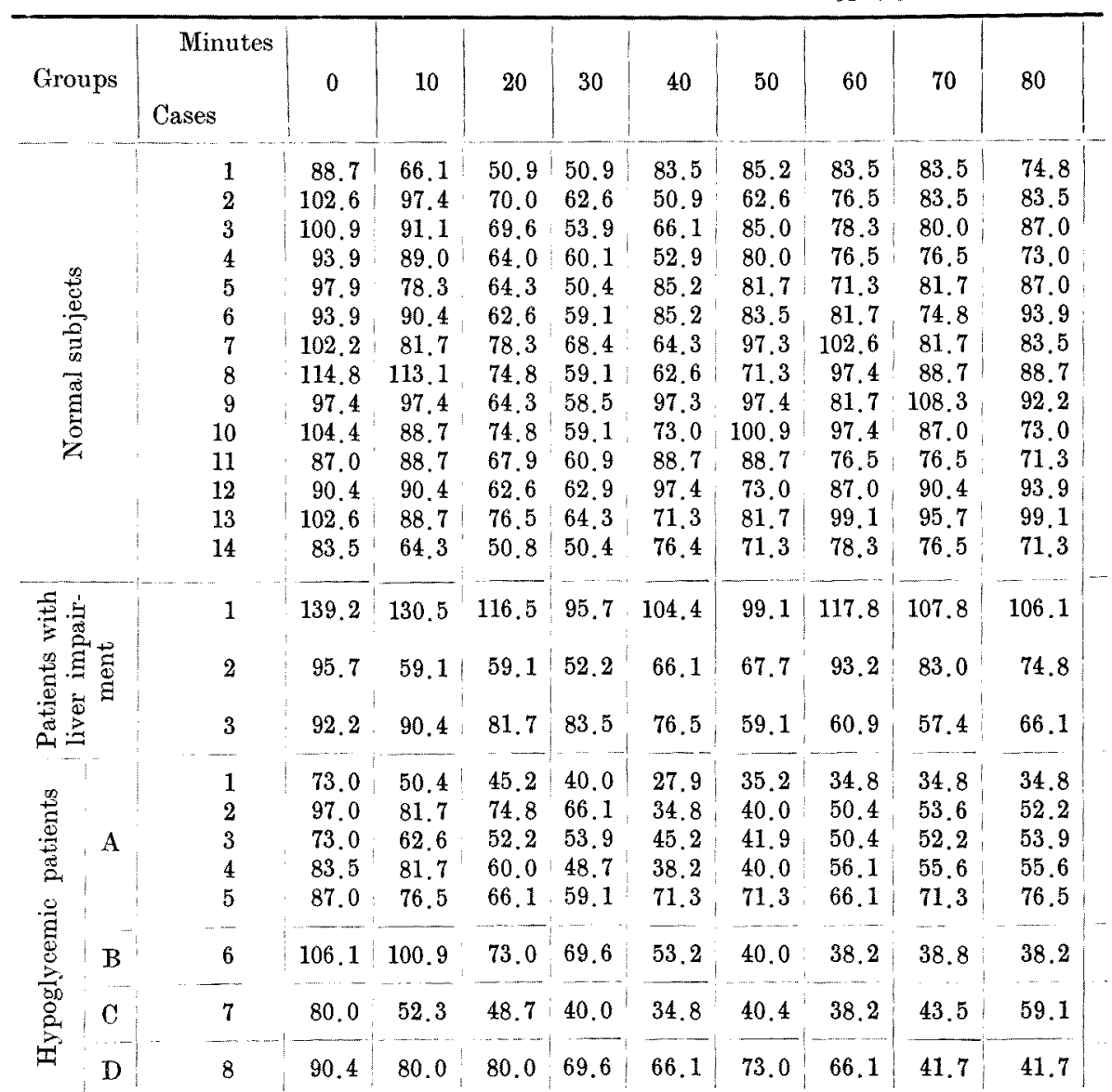

A: Functional hypoglycemia

B: Hypoglycemia due to hypoadrenalism

hypoglycemic symptoms. A trend of gradual recovery was thereafter observed, and a peak of $52.2 \mathrm{mg} / 100 \mathrm{ml}$ was reached at 130 minutes. The blood sugar thereafter remained at stationary values.

A hypoglycemic patient with hypoadrenalism showed fluctuations in blood sugar levels, as shown in Fig. 5. A rapid decline of blood sugar took place following the intravenous injection of Na-tolbutamide from the fasting blood sugar level of $106.1 \mathrm{mg} / 100 \mathrm{ml}$ to the minimum of $38.2 \mathrm{mg} / 100 \mathrm{ml}$ at 60 minutes. The blood sugar showed subsequently a gradual rise to a peak of $67.9 \mathrm{mg} / 100 \mathrm{ml}$ at 150 minutes and thereafter remained stationary.

A patient with pancreatic hyperinsulinism showed blood sugar fluctuations as shown in Fig. 6. A rapid decline took place following the intravenous injection of Na-tolbutamide from the fasting blood sugar level of $80.0 \mathrm{mg} / 100 \mathrm{ml}$ to a nadir of $34.8 \mathrm{mg} / 100 \mathrm{ml}$ at 40 minutes. The level thereafter tended to rise gradually and 
Na-tolbutamide $(1 \mathrm{~g})$ in normal subjects, patients with liver impairment, and $(\mathrm{mg} / 100 \mathrm{ml})$

\begin{tabular}{|c|c|c|c|c|c|c|c|c|c|c|c|c|c|}
\hline 90 & 100 & 110 & 120 & 130 & 140 & 150 & 160 & 170 & 180 & 210 & 240 & 270 & 300 \\
\hline 76.5 & 78.5 & 80.4 & 83.5 & 79.6 & 75.6 & 71.3 & 71.8 & 73.0 & 76.5 & 70.4 & 73.0 & 76.5 & 71.3 \\
\hline 81.7 & 71.3 & 74.8 & 74.8 & 81.7 & 81.7 & 81.7 & 81.7 & 81.7 & 76.5 & 78.3 & 74.8 & 78.3 & 76.5 \\
\hline 88.7 & 78.3 & 78.3 & 90.4 & 90.4 & 90.4 & 80.0 & 87.0 & 81.7 & 74.3 & 80.0 & 76.5 & 74.8 & 76.5 \\
\hline 76.5 & 76.5 & 76.5 & 83.5 & 71.3 & 73.0 & 73.0 & 73.0 & 73.0 & 73.0 & 78.3 & 76.5 & 73.0 & 76.5 \\
\hline 80.4 & 82.2 & 71.3 & 88.7 & 74.8 & 73.0 & 78.0 & 95.9 & 102.6 & 78.3 & 93.9 & 92.2 & 83.2 & 85.2 \\
\hline 104.4 & 78.3 & 83.5 & 80.0 & 113.1 & 102.6 & 97.4 & 69.6 & 69.6 & 69.6 & 71.3 & 76.5 & 71.3 & 73.2 \\
\hline 83.5 & 88.7 & 88.7 & 87.0 & 90.4 & 88.7 & 90.4 & 85.2 & 88.7 & 85.2 & 87.0 & 87.0 & 85.2 & 87.6 \\
\hline 97.4 & 80.6 & 83.5 & 93.9 & 93.9 & 90.4 & 85.2 & 90.4 & 93.9 & 78.3 & 83.9 & 74.8 & 83.5 & 81.2 \\
\hline 109.1 & 92.2 & 87.0 & 100.9 & 80.0 & 95.7 & 78.3 & 76.5 & 88.7 & 85.2 & 87.0 & 90.4 & 85.2 & 83.5 \\
\hline 78.3 & 90.4 & 74.8 & 95.7 & 76.5 & 71.3 & 104.4 & 93.9 & 95.7 & 85.2 & 85.2 & 76.5 & 83.5 & 78.0 \\
\hline 80.4 & 83.5 & 83.5 & 83.5 & 80.9 & 77.5 & 79.1 & 74.8 & 78.3 & 77.9 & 76.5 & 74.8 & 74.8 & 80.0 \\
\hline 97.4 & 81.9 & 83.5 & 73.0 & 76.5 & 80.0 & 83.5 & 78.3 & 87.0 & 78.0 & 85.2 & 85.2 & 85.2 & 85.2 \\
\hline 90.4 & 90.4 & 169.6 & 83.5 & 92.2 & 80.0 & 80.0 & 80.0 & 90.4 & 85.2 & 87.0 & 88.7 & 85.2 & 87.0 \\
\hline 71.3 & 73.0 & 71.3 & 72.2 & 71.3 & 71.3 & 71.3 & 71.3 & 71.3 & 71.3 & 81.7 & 73.0 & 73.0 & 71.3 \\
\hline 104.4 & 92.7 & 87.0 & 88.7 & 85.2 & 95.7 & 95.7 & 80.0 & 83.5 & 80.4 & 83.5 & 80.0 & 81.7 & 71.3 \\
\hline 74.8 & 74.8 & 73.0 & 82.2 & 78.3 & 80.0 & 71.3 & 78.3 & 71.3 & 73.0 & 80.3 & 80.0 & 81.7 & 78.3 \\
\hline 64.3 & 73.0 & 66.1 & 80.4 & 103.1 & 94.8 & 71.3 & 74.8 & 71.3 & 76.5 & 73.0 & 73.0 & 76.5 & 71.3 \\
\hline 34.8 & 40.0 & 45 & 3.7 & 52.2 & 52.2 & 52.2 & 50.4 & 50.4 & 50.7 & 51.4 & & 60.9 & 59.1 \\
\hline 57.4 & 67.6 & 56.5 & 48.5 & 36.5 & 34.8 & 34.8 & 48.7 & 60.9 & 54.8 & 64.8 & 57.4 & 67.9 & 67.9 \\
\hline 57.4 & 59.0 & 62.6 & 66.1 & 59.0 & 59.0 & 60.9 & 62.6 & 60.9 & 60.9 & 60.9 & 60.9 & 60.9 & 66.2 \\
\hline 80.0 & 78.0 & 44.8 & 45.2 & 45.2 & 67.9 & 70.5 & 75.2 & 71.3 & 73.5 & 64.3 & 63.4 & 60.8 & 63.4 \\
\hline 67.6 & 66.3 & 40.7 & 50.4 & 48.7 & 60.9 & 66.1 & 69.6 & 69.6 & 70.3 & 71.0 & 60.9 & 60.9 & 60.9 \\
\hline 38.2 & 38.8 & 40.0 & 53.9 & 53.2 & 60.2 & 67.9 & 62.8 & 62.5 & 62.6 & 64.3 & 66.1 & 62.6 & 62.6 \\
\hline 40.0 & 50.4 & 73.5 & 67.9 & 67.9 & 57.4 & 57.4 & 52.2 & 50.4 & 48.7 & 66.1 & 57.4 & 48.7 & 46.5 \\
\hline 50.4 & 46.9 & 57.4 & 53.9 & 62.6 & 59.1 & 57.4 & 57.4 & 53.9 & 67.9 & 57.9 & 57.9 & 53.9 & 53.9 \\
\hline
\end{tabular}

recorded a peak of $73.5 \mathrm{mg} / 100 \mathrm{ml}$ at 110 minutes. It is interesting that the blood sugar level thus exhibited a tendency to recover. The level thereafter gradually declined and then attained a stationary condition.

A diabetic patient with hypoglycemia showed the blood sugar fluctuations as shown in Fig. 7. The blood sugar gradually fell from the fasting blood sugar level of $90.4 \mathrm{mg} / 100 \mathrm{ml}$ following the intravenous Na-tolbutamide injection. A nadir of $41.7 \mathrm{mg} / 100 \mathrm{ml}$ was registered at 70 minutes. The blood sugar level thereafter tended to rise and reached a peak of $67.9 \mathrm{mg} / 100 \mathrm{ml}$ at 180 minutes, after which it remained stationary.

The maximum decline rate, sensitivity index, recovery index, and decline index had been employed by the author ${ }^{6}$ as the insulin blood sugar reactions for the purpose of screening hypoglycemia and all these factors were determined on the present author's subjects. The results of the determinations are presented 
TABLE 2. The per cent declines of the blood sugar levels at 20,30,60,90,120,150, 180,240 and 300 minutes after the injection of $\mathrm{Na}$-tolbutamide $(1 \mathrm{~g})$

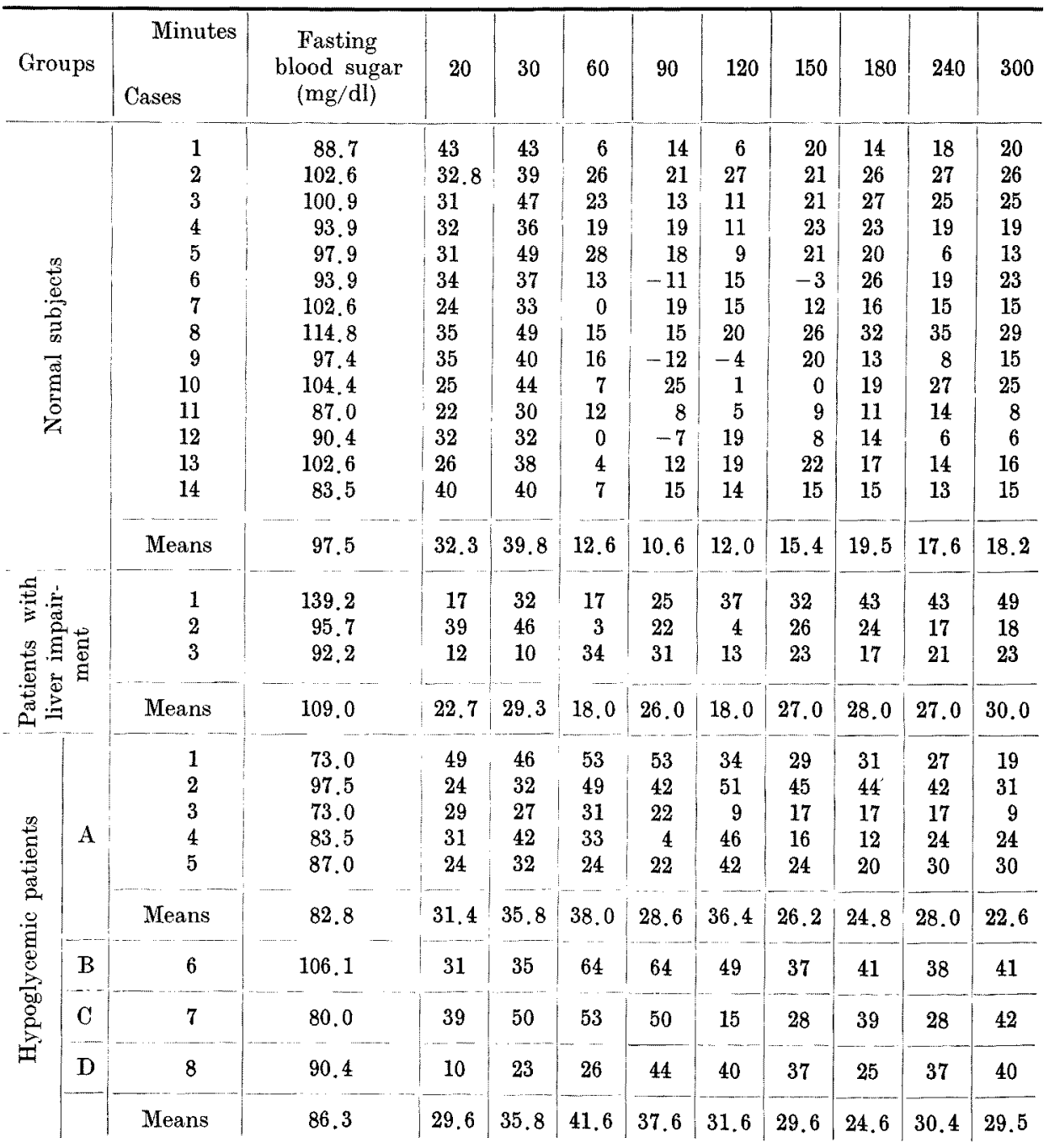

A: Functional hypoglycemia B: Hypoglycemia due to hypoadrenalism C: Organic pancreatic hyperinsulinism D: Diabetic patient complicated with hypoglycemia

in Table 3.

The results of the present experiments indicate that the decline index in hypoglycemic cases following the intravenous injection of Na-tolbutamide showed a mean of 0.95 which was only a little lower than that of the normal group, whereas the recovery index in the hypoglycemic cases had a mean of 0.37 which was evidently different from the mean of the normal subjects. Therefore, the stationary values in the hypoglycemic patients had a mean of $59.3 \mathrm{mg} / 100 \mathrm{ml}$, which was markedly lower than that in the normal subjects. 


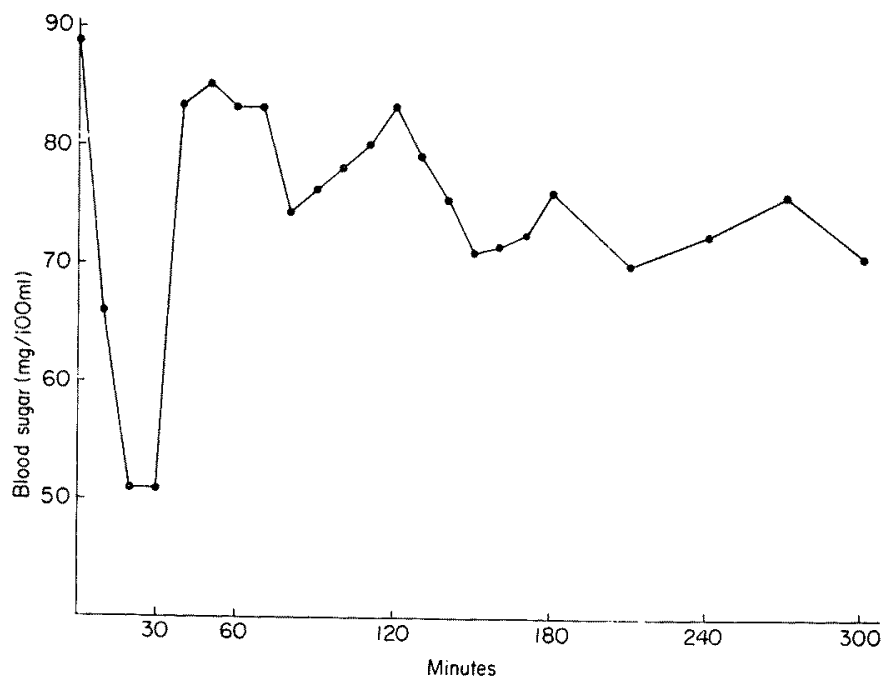

Fig. 2. The blood sugar variations following the intravenous injection of Na-tolbutamide $(\mathrm{lg})$ in a normal subject. Case 1 .

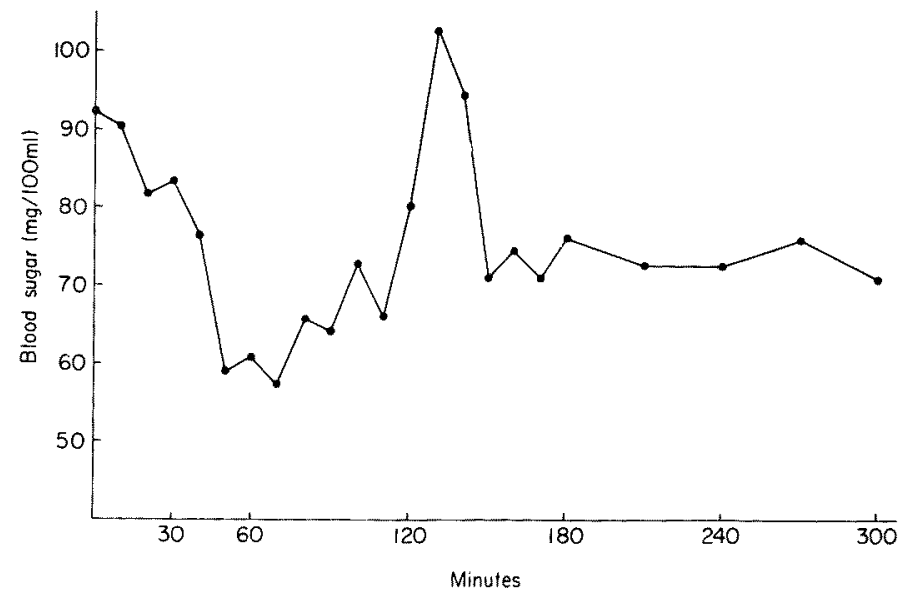

Fig. 3. The blood sugar variations following the intravenous injection of Na-tolbutamide $(1 \mathrm{~g})$ in Case 3 of the group with liver impairment.

The Na-tolbutamide sensitivity index was ranging from 0.93 to 2.13 with a mean of 1.41 in normal subjects; in patients with liver function disturbance, the index was 0.53 to 1.51 with a mean of 1.03 ; and in hypoglycemic patients, it was 0.48 to 1.01 , the mean being 1.10. Thus, there was no significant difference in the Na-tolbutamide sensitivity index between normal subjects and patients with liver function disturbance.

Therefore, it seems to be impossible to make differentiation among the abovementioned three groups, when only the sensitivity index to the nadir after the intravenous injection of Na-tolbutamide is taken into consideration. 
TABLE 3. The minimum decline rate, sensitivity index, recovery

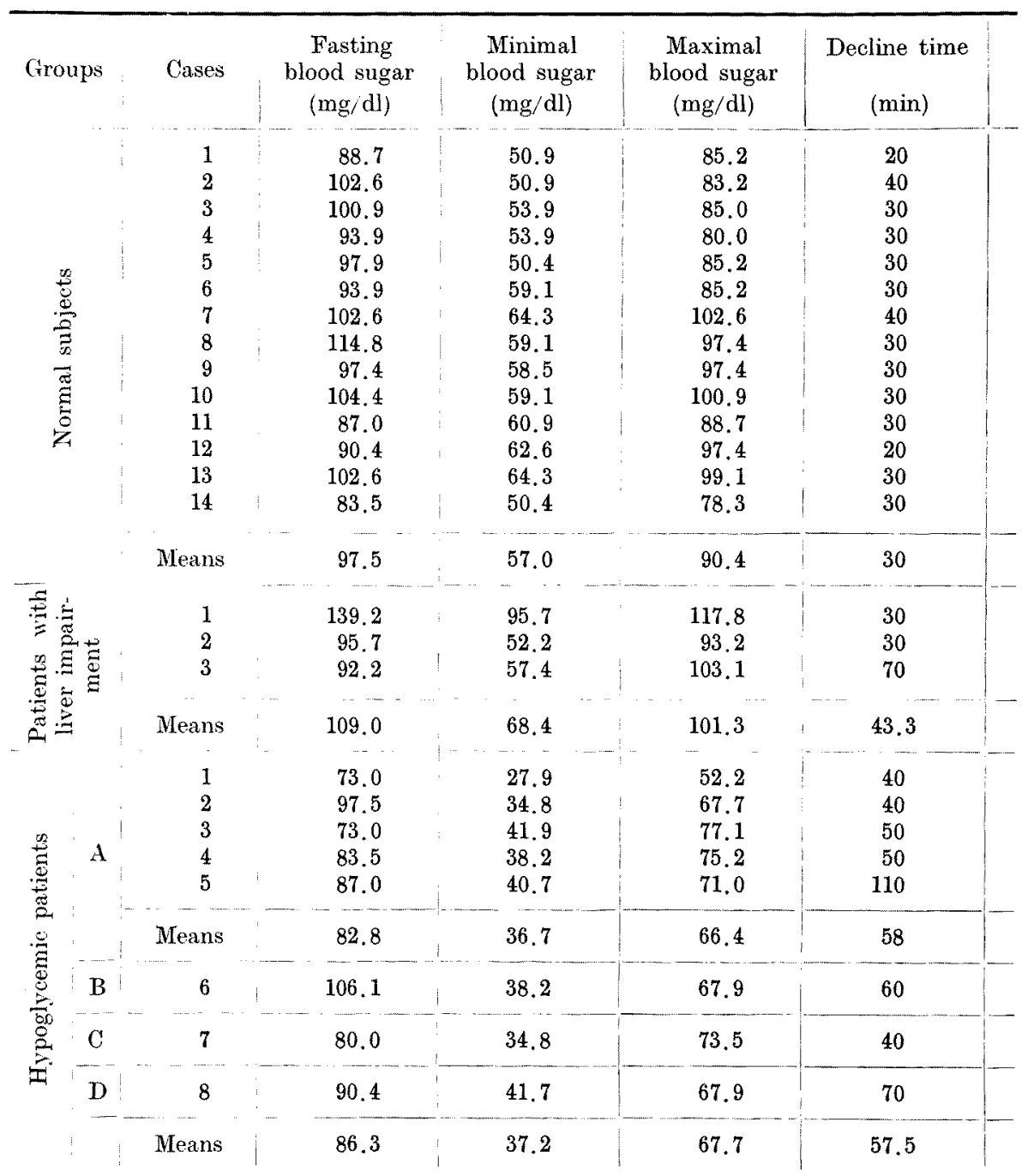
A: Functional hypoglycemia
B: Hypoglycemia due to hypoadrenalism
C: Organic

On the other hand, the decline rate, minimum value, maximum value, decline time, recovery time, maximum decline rate, sensitivity index, decline index, and recovery index in the various types of hypoglycemia were shown in Table 2; the decline rates at 20 minutes after the intravenous injection of $\mathrm{Na}$ tolbutamide in functional hypoglycemia, hypoglycemia due to hypoadrenalism, and pancreatic hyperinsulinism were $31.4 \%, 31 \%$ and $39 \%$, respectively. The comparable values at 30 minutes were $35.8 \%, 35 \%$ and $50 \%$. The decline rates at 20 and 30 minutes were highest in pancreatic hyperinsulinism, the values being $39 \%$ and $50 \%$, respectively. 
index, and decline index in the Na-tolbutamide test $(1 \mathrm{~g})$

\begin{tabular}{|c|c|c|c|c|c|}
\hline $\begin{array}{c}\text { Recovery } \\
\text { time } \\
(\mathrm{min})\end{array}$ & $\begin{array}{l}\text { Decline } \\
\text { index }\end{array}$ & $\begin{array}{l}\text { Recovery } \\
\text { index }\end{array}$ & $\begin{array}{l}\text { Sensitivity } \\
\text { index }\end{array}$ & $\begin{array}{c}\text { Maximal } \\
\text { decline rate } \\
(\%)\end{array}$ & $\begin{array}{c}\text { Stationary } \\
\text { value } \\
(\mathrm{mg} / \mathrm{dl})\end{array}$ \\
\hline 30 & 1.89 & 1.14 & 2.13 & 42.6 & 73.9 \\
\hline 30 & 1.29 & 1.08 & 1.26 & 50.4 & 78.2 \\
\hline 20 & 1.56 & 1.55 & 1.55 & 46.6 & 78.7 \\
\hline 10 & 1.33 & 2.61 & 1.41 & 42.6 & 74.1 \\
\hline 10 & 1.18 & 3.48 & 1.61 & 48.5 & 88.6 \\
\hline 10 & 1.16 & 2.61 & 1.24 & 37.1 & 71.5 \\
\hline 20 & 0.96 & 1.91 & 0.93 & 37.3 & 86.3 \\
\hline 30 & 1.86 & 1.28 & 1.60 & 48.5 & 80.3 \\
\hline 20 & 1.29 & 1.92 & 1.32 & 39.8 & 86.6 \\
\hline 20 & 1.51 & 2.09 & 1.45 & 43.4 & 81.7 \\
\hline 10 & 0.87 & 2.78 & 10.0 & 30.0 & 78.9 \\
\hline 20 & 1.39 & 1.74 & 1.54 & 30.8 & 81.7 \\
\hline 30 & 1.29 & 1.16 & 1.26 & 37.3 & 84.8 \\
\hline 30 & 1.10 & 0.93 & 1.32 & 39.6 & 73.1 \\
\hline 20.7 & 1.36 & 1.88 & 1.41 & 41.0 & 76.3 \\
\hline 30 & 1.45 & 0.77 & 1.04 & 31.2 & 80.1 \\
\hline 30 & 1.45 & 1.33 & 1.51 & 45.4 & 76.8 \\
\hline 60 & 0.49 & 0.76 & 0.53 & 37.7 & 74.7 \\
\hline 40 & 1.13 & 0.82 & 1.03 & 38.1 & 77.2 \\
\hline 90 & 1.13 & 0.27 & 1.54 & 61.7 & 53.3 \\
\hline 60 & 1.57 & 0.55 & 1.61 & 64.3 & 64.5 \\
\hline 70 & 0.62 & 0.34 & 0.85 & 42.6 & 61.2 \\
\hline 110 & 0.91 & 0.36 & 1.08 & 54.2 & 62.9 \\
\hline 100 & 0.42 & 0.20 & 0.48 & 53.2 & 60.9 \\
\hline 86 & 0.93 & 0.35 & 1.12 & 55.2 & 60.6 \\
\hline 90 & 1.13 & 0.44 & 1.06 & 63.9 & 63.5 \\
\hline 70 & 1.13 & 0.55 & 1.41 & 56.5 & 52.7 \\
\hline 110 & 0.69 & 0.23 & 0.76 & 53.8 & 55.9 \\
\hline 87.1 & 0.95 & 0.37 & 1.10 & 56.2 & 59.3 \\
\hline
\end{tabular}

pancreatic hyperinsulinism

D: Diabetic patient complicated with hypoglycemia

The decline rate was lowest in the diabetic patient complicated with hypoglycemia, being $10 \%$ at 20 minutes and $23 \%$ at 30 minutes. Thus, considering from the rate of decline at 20 and 30 minutes, this patient fulfilled the diagnostic criteria of diabetes mellitus.

The rates of decline at 60 minutes in the four types of hypoglycemia were $38 \%, 64 \%, 53 \%$ and $26 \%$, respectively, the lowest rate being found in diabetes complicated with hypoglycemia. At 90 minutes, however, there was little difference in the rates among the 4 groups, the values being $28.6 \%, 64 \%, 50 \%$ and $44 \%$, respectively. 


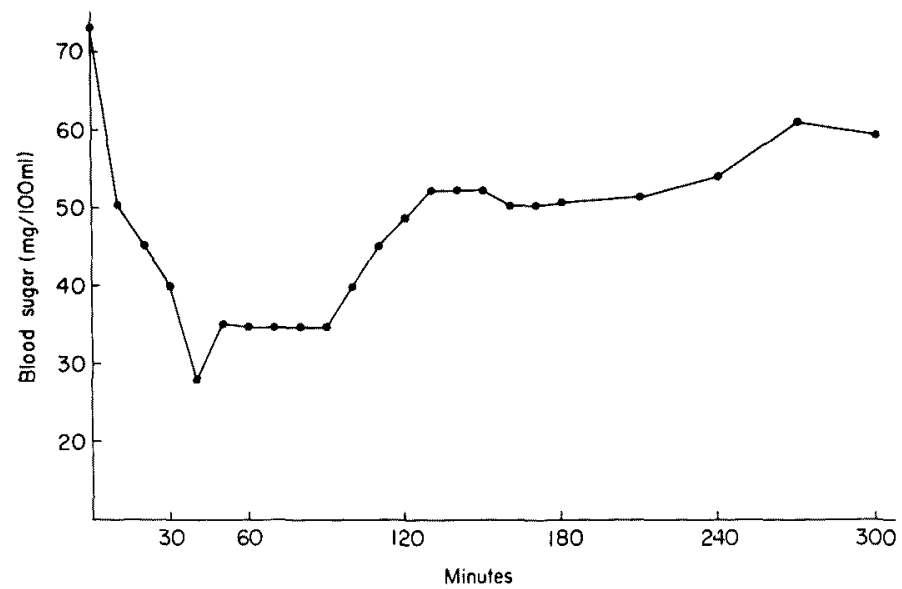

Fig. 4. The blood sugar variations following the intravenous injection of Na-tolbutamide $(1 \mathrm{~g})$ in Case 1 of the group with functional hypoglycemia.

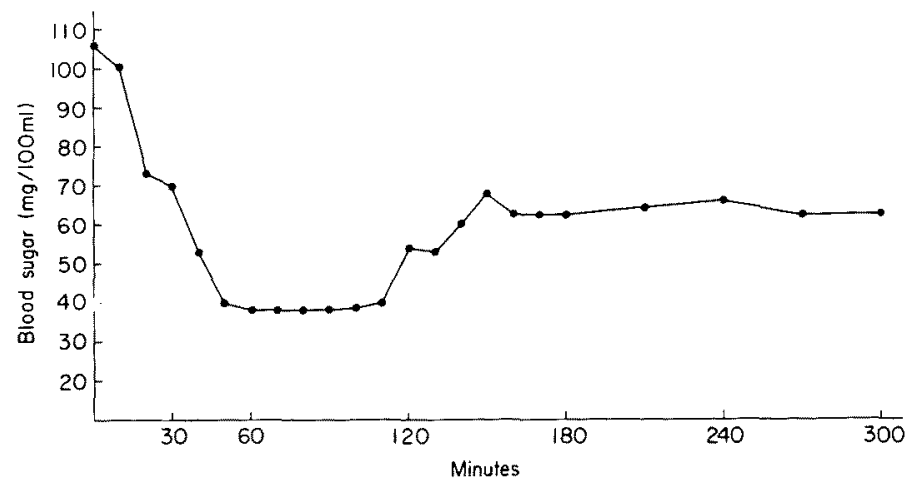

Fig. 5. The blood sugar variations following the intravenous injection of Na-tolbutamide $(1 \mathrm{~g})$ in a hypoglycemic patient with hypoadrenalism.

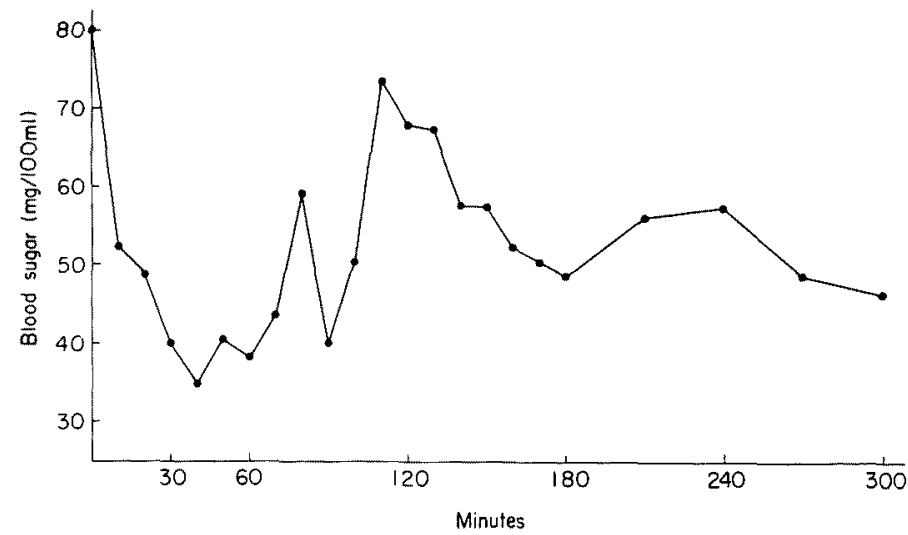

Fig. 6. The blood sugar variations following the intravenous injection of Na-tolbutamide $(\mathrm{g})$ in a patient with pancreatic hyperinsulinism. 


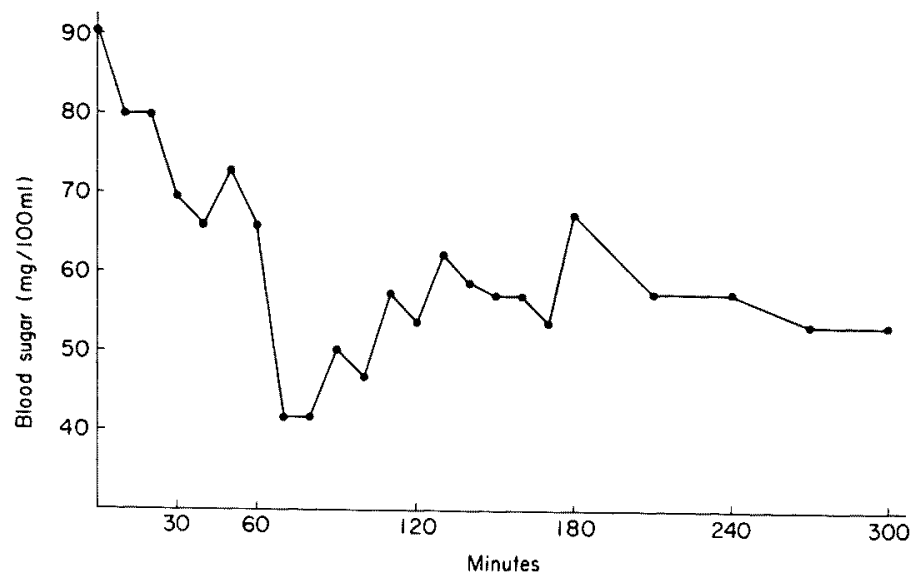

Fig. 7. The blood sugar variations following the intravenous injection of Na-tolbutamide $(\mathrm{g})$ in the diabetic patient with hypoglycemia.

The lowest values of blood sugar in the four types ranged from 27.9 to 41.9 $\mathrm{mg} / 100 \mathrm{ml}$, while the highest value, $73.5 \mathrm{mg} / 100 \mathrm{ml}$, was found in the patient with pancreatic hyperinsulinism.

Both the decline time and recovery time were longest in diabetics complicated with hypoglycemia, being 70 minutes and 110 minutes, respectively. The decline index in the four types was $0.94,1.13,1.13$ and 0.69 , respectively, the lowest index being found in the diabetic patient complicated with hypoglycemia.

The recovery indices which were found to be $0.35,0.44,0.55$ and 0.23 in functional hypoglycemia, hypoglycemia due to hypoadrenalism, pancreatic hyperinsulinism, and diabetes complicated by hypoglycemia, respectively, were evidently different from those of the normal group and of the group with liver function disturbance. The stationary values were $60.6 \mathrm{mg} / 100 \mathrm{ml}, 63.5 \mathrm{mg} / 100 \mathrm{ml}, 52.7$ $\mathrm{mg} / 100 \mathrm{ml}$, and $55.9 \mathrm{mg} / 100 \mathrm{ml}$, respectively.

Thus, the various types of hypoglycemia following the intravenous injection of Na-tolbutamide showed various patterns of reaction, mainly on account of different abilities of recovery from hypoglycemia.

The rate of decline was largest in pancreatic hyperinsulinism and smallest in diabetes complicated with hypoglycemia. In the case of pancreatic hyperinsulinism severe hypoglycemia was not sustained over 3 hours, but the blood sugar level exhibited only a temporary rise. In the case of functional hypoglycemia, hypoglycemia persisted as long as five hours associated with loss of consciousness. The contrast was remarkable.

In 2 cases of hypoglycemia and in a case of pancreatic hyperinsulinism, the blood sugar level fluctuations following the intravenous $\mathrm{Na}$-tolbutamide were biphasic, this being also a very interesting finding. 


\section{Discussion}

The diagnostic technique for hypoglycemia using intravenous injection of $\mathrm{Na}$ tolbutamide was explored first by Fajans and later by Pfeiffer et al., ${ }^{7}$ Frawley et $a l .{ }^{8}$ and Creutzfeldt et $a l .{ }^{9}$ The principle of the diagnostic method has been regarded to consist in the confirmed observation of very low blood sugar level after intravenous tolbutamide injection sustained for more than three hours, which is particularly evident in cases of insuloma. It is further acknowledged that the technique is useful for differential diagnosis of various hypoglycemia including functional hypoglycemia.

It is suggested that a large amount of insulin is secreted from the pancreatic tumor following the intravenous Na-tolbutamide injection, whereas a release of such an amount of insulin does not take place in functional hypoglycemia. In the latter case insulin secretion is increased probably by carbohydrate loading.

The author has carried out precise studies on the problem of blood sugar in various types of hypoglycemia. ${ }^{11-14}$ It is well known that the differential diagnosis of various types of hypoglycemia cannot always be achieved satisfactorily with the glucose tolerance test. For example, it is often difficult in functional hypoglycemia, which is most frequently encountered, to find any difference in the glucose tolerance curves from the normal. As has been shown in the glucose tolerance test on the patients after gastric surgery, the patients often do not exhibit hypoglycemic symptoms despite the presence of terminal hypoglycemic state.

This indicates that for the development of hypoglycemic symptoms a temporary low blood sugar level is not important but a sustained low blood sugar level may be of significance.

The Na-tolbutamide blood-sugar reaction in hypoglycemia may be influenced by three factors; firstly, the fasting blood sugar level; secondly, the speed of blood sugar decline; and thirdly, the speed of recovery from the low blood sugar level.

Apart from pancreatic hyperinsulinism, it is well known that an extremely low level of fasting blood sugar is observed in hepatic hypoglycemia.

The author has carefully studied the rate of decline and the rate of recovery of blood sugar level after tolbutamide injection. The mean index of decline was 1.36 in normal subjects, 0.93 in functional hypoglycemia, 1.13 in hypoglycemia due to hypoadrenalism, 1.13 in pancreatic hyperinsulinism, and 0.69 in diabetes complicated with hypoglycemia. The values determined from the sensitivity test described by Saito ${ }^{16,17}$ were 1.41 for the mean of normal subjects with a range from 0.48 to 1.61 , and 1.10 for the mean of the hypoglycemic group, where the means were 1.12 for functional hypoglycemia, 1.06 for hypoglycemia due to hypoadrenalism, 1.41 for pancreatic hyperinsulinism, and 0.76 for diabetes complicated with hypoglycemia. Thus, neither the index of decline nor the index of sensitivity was satisfactory for the differential diagnosis of various types of hypoglycemia. 
While the insulin sensitivity index, which I had advocated on account of its diagnostic value, was less than 17 in all the types of hypoglycemia, the intravenous $\mathrm{Na}$-tolbutamide test was not found sensitive enough to differentiate hypoglycemic patients from normal subjects. As will be described later, an extremely low rate of recovery from hypoglycemic value is not necessarily predicted from the rate of blood sugar decline according to my experience.

The third factor was the speed of recovery, and the recovery indices were $0.35,0.44,0.55$ and 0.23 , in functional hypoglycemia, hypoglycemia due to hypoadrenalism, pancreatic hyperinsulinism, and diabetes complicated with hypoglycemia, respectively. The speed of recovery in hypoglycemia was thus distinctly different from that of normal subjects and that of liver damaged group.

The characteristic finding after the intravenous tolbutamide injection in various types of hypoglycemia was an insufficient recovery ability of blood sugar levels in all the cases. Among the three factors already cited, the one contributing to the development of sustained hypoglycemia seems to be the suppressed recovery rate. The defective recovery is almost always observed in cases of hypoglycemia and can be regarded as the only factor with which the diagnosis of hypoglycemia is substantiated.

The persistence of pronounced hypoglycemia after intravenous Na-tolbutamide injection was reported by Fajans and Schneider ${ }^{4}$ and it was observed in 2 of the author's own cases of functional hypoglycemia. In one of them the patient had received gastric surgery. Both patients were in a comatose state during the course of the experiment. Before the experiment, these patients had ingested a diet which contained $300 \mathrm{~g}$ of carbohydrate, $70 \mathrm{~g}$ of protein, and at least $50 \mathrm{~g}$ of fat per day. The result of various examinations, too, ruled out pancreatic hyperinsulinism of these patients.

In the patient with a definite diagnosis of pancreatic hyperinsulinism, whose diffuse hyperplasia of the islets was demonstrated by histologic examination on specimens of subtotal pancreatectomy, the blood sugar level showed a temporary elevation 110 minutes after intravenous tolbutamide injection and subsequently shifted to lower levels. This was a very interesting finding, because it provided the evidence against the view of Fajans and Schneider that persistent hypoglycemia after intravenous tolbutaidme injection was observed in all the cases with insulinoma. The above-mentioned phenomenon can also be reproduced by subcutaneous insulin injection in hypoglycemic patients, and the blood sugar curve alone after intravenous tolbutamide injection does not necessarily point to Na-tolbutamide as accounting for insulin secretion from the tumor.

\section{Acknowledgment}

I am indebted to Prof. Tatsuo Saito, the Research Institute for Tuberculosis, Leprosy and Cancer, Tohoku University for the revision of the manuscript. 


\section{References}

1) Mirsky, A.I., Diengott, D. \& Dolger, H. The relation of various variables to the hypoglycemic action of 1-butyl-3-p-tolylsulfonyl-urea in patients with diabetes mellitus. Metabolism, 1956, 5, 875-893.

2) Unger, R.H. \& Madison, L.L. A new diagnostic procedure for mild diabetes mellitus. Evaluation of an intravenous Tolbutamide response test. Diabetes, 1958, 7, 455-461.

3) Unger, R.H. \& Madison, L.L. Comparison of response to intravenously administered sodium-Tolbutamide in mild diabetic and nondiabetie subjects. $J$. clin. Invest., $1958,37,627-630$.

4) Fajans, S.S., Schneider, M.J., Schteingart, E.D. \& Conn, W.J. The diagnostic value of sodium-Tolbutamide in hypoglycemic states. J. clin. Endocr., 1961, 21, 371-386.

5) Fujita, A. \& Iwatake, D. Blood sugar determination method by yeast procedure. Tokyo Igaku Zasshi (Jap.), 1931, No. 2739, 1865-1870, and 1931, No. 2740. 19051908.

6) Yoshikawa, K. Advocation of insulin reaction test as the screening for hypoglycemia. Tohoku J. exp. Med., 1962, 76, 204-214.

7) Pfeiffer, E.F., Pfeiffer, M., Ditschuneit, H. \& Chang-Su Ahn. Clinical and experimental studies of insulin secretion following Tolbutamide and Metahexamide administration. Ann. N.Y. Acad. Sci., 1959, 82, 479-495.

8) Frawley, T.F., Kistler, H. \& Shelley, T. Effects of anti-inflammatory steroids on carbohydrate metabolism, with emphasis on hypoglycemic and diabetic states. Ann. N.Y. Acad. Sci., 1959, 82, 868-885.

9) Creutzfeld, W., Wille, K. \& Kaup, H. Intravenöse Belastungen mit Glucose, Insulin und Tolbutamide bei Gesunden, Diabetikern, Leberzirrhotikern und Insulomaträgern. Dtsch. med. Wschr., 1962, 87, 2189-2195.

10) Yoshikawa, K., Kilkuchi, S., Hoshi, A., Suzuki, Z. \& Trie, K. Hypoglycemia due to diffuse hyperplasia of pancreatic islets of Langerhans. Naika (Jap.), 1958, 2, 584.

II) Yoshikawa, K., Hoshi, A., Sasao, K., Endo, E. \& Suzuki, Z. Spontaneous hypoglycemia centering around two cases. Nissho-kai-shi (Jap.), 1958, 55, 402.

12) Yoshikawa, K., Endo, E. \& Watanabe, Y. One case of spontaneous hypoglycemia accompanied by Simons' syndrome. Nissho-kai-shi (Jap.), 1960, 57, 705.

13) Yoshikawa, K., Endo, E. \& Watanabe, Y. One case of functional hypoglycemia. Nissho-kai-shi (Jap.), 1959, 56, 341.

14) Yoshikawa, K., Sasao, K., Watanabe, Y. \& Anzai, S. Studies on hypoglycemia after gastric operations. Nissho-kai-shi (Jap.), 1961, 58, 518.

15) Saito, T. Insulin sensitivity in diabetes mellitus. Tohoku J. exp. Med., 1953, 57, 393-401.

16) Saito, T. Adrenalin reaction in diabetes mellitus. Tohoku J. exp. Med., 1953, 58, $1-9$. 